\title{
Synthesis of 2-(1-Benzofuran-2-yl)-4-(1,3-benzoxazol-2-yl/ 1,3-benzothiazol-2-yl) Quinolines as Blue Green Fluorescent Probes
}

\author{
Yadav D. Bodke, ${ }^{1}$ Sheelavanth Shankerrao, ${ }^{1}$ and Hosanagara N. Harishkumar ${ }^{2}$ \\ ${ }^{1}$ Department of P. G. Studies and Research in Industrial Chemistry, School of Chemical Sciences, Kuvempu University, Shivamogga, \\ Karnataka, Shankaraghatta 577 451, India \\ ${ }^{2}$ Department of P. G. Studies and Research in Chemistry, School of Chemical Sciences, Kuvempu University, Shivamogga, Karnataka, \\ Shankaraghatta 577 451, India \\ Correspondence should be addressed to Yadav D. Bodke; ydbodke@gmail.com
}

Received 8 June 2012; Revised 29 August 2012; Accepted 7 September 2012

Academic Editor: José M. G. Martinho

Copyright (C) 2013 Yadav D. Bodke et al. This is an open access article distributed under the Creative Commons Attribution License, which permits unrestricted use, distribution, and reproduction in any medium, provided the original work is properly cited.

\begin{abstract}
A series of novel 2-(1-benzofuran-2-yl)-4-(1,3 benzoxazol-2-yl/1,3-benzothiazol-2-yl) quinoline derivatives $4(\mathbf{a}-\mathbf{d})$ were synthesized in one step by the reaction of 2-(1-benzofuran-2-yl) quinoline-4-carboxylic acids 3(a-b) with o-aminophenol and o-amino thiophenol, respectively, using polyphosphoric acid (PPA) as a cyclizing agent. The fluorescent properties of newly synthesized compounds were investigated in three different organic solvents like chloroform $\left(\mathrm{CHCl}_{3}\right)$, tetrahydrofuran (THF), and dimethyl sulfoxide (DMSO). The photophysical constants such as quantum yield and stokes shift were determined. From the results of fluorescence study, it is evident that all synthesized compounds are fluorescent in solution. Compound 4a emitted green light $(490.4 \mathrm{~nm}, 518.2 \mathrm{~nm}$, and $522.4 \mathrm{~nm})$ with high quantum yield in all the three solvents, while compounds $\mathbf{4 b}$, $\mathbf{4 c}$, and $\mathbf{4 d}$ emitted green light $(512 \mathrm{~nm}, 499 \mathrm{~nm}, 510 \mathrm{~nm})$ only in polar solvent DMSO. All fluorescent probes exhibited a bathochromic shift on increase in polarity of the solvent.
\end{abstract}

\section{Introduction}

There is an ever-increasing interest in the development of efficient photoluminescent materials especially those which emit light in the blue region of the visible spectrum. These materials play a vital role in optoelectronic devices such as tunable lasers and amplifiers, optical fibers, switches, or modulators with diverse applications in optical communications, photonics, medicines, optical spectroscopy, and organic electroluminescent diode (OLED) [1].

Among the various nitrogen-containing heterocyclic compounds, quinolines occur predominately in nature appreciable to their stability and ease of generation. They exhibit pronounced biological activities [2], and many derivatives have been reported to possess fluorescent property, having wide application as organic electroluminescent devices $[3,4]$, biosensors [5, 6], detection of metal ions [7-9], and so forth. On the other hand, benzofuran chromophore with high photoluminescence (PL) and quantum efficiencies [10] found wide application as organic electroluminescent devices [11-13] and chemosensors [14, 15].

The present work describes the synthesis and characterization of six new dyes. Initially the two derivatives of 2(1-benzofuran-2-yl) quinoline-4-carboxylic acid 3(a-b) were synthesized, and it was found that they emit light in the blue region of the spectrum. Further it was planned to modify the carboxylic acid functionality by electron donor benzoxazole and benzothiazole ring system. Therefore, the present investigation involves the synthesis and fluorescent studies of new 2-(1-benzofuran-2-yl)-4-(1,3-benzoxazol-2yl/1,3-benzothiazol-2-yl) quinoline derivatives $4(\mathbf{a}-\mathbf{d})$ with a motive of getting possible application as blue OLE materials. Here we selected an unique combination of three different fused heterocyclic ring systems, where quinoline ring acts as core moiety, benzofuran nucleus substituted at second position acts as chromophore, and 3-benzoxazol-2-yl 


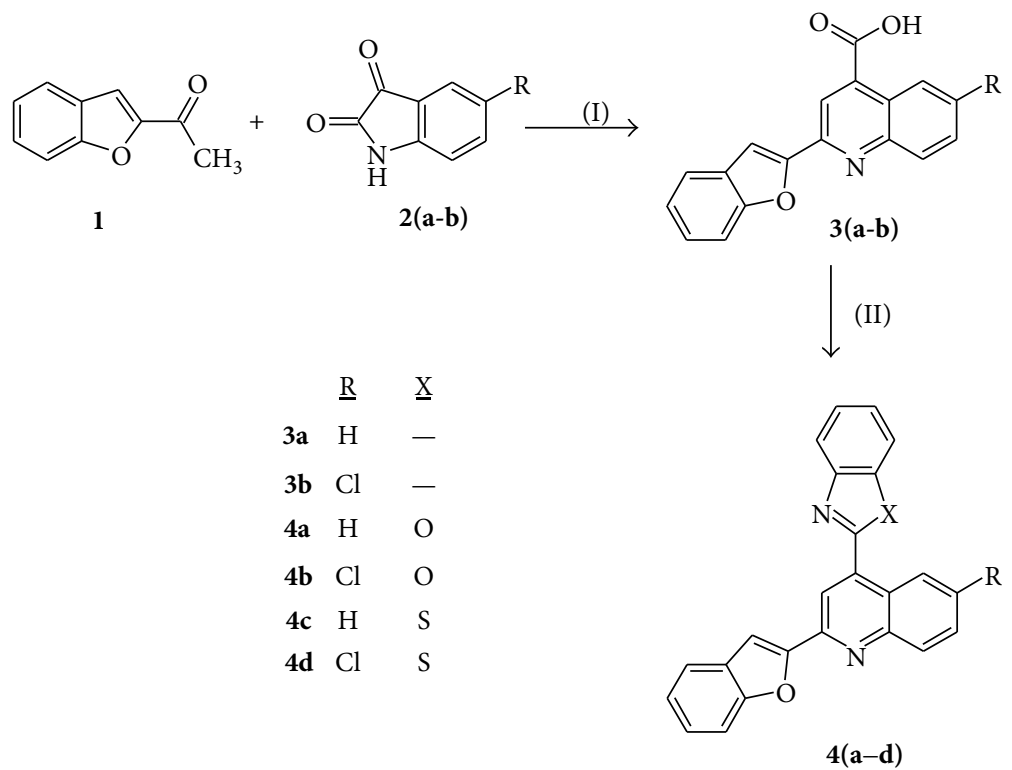

(I) Aq. $\mathrm{KOH} / \mathrm{EtOH}$, reflux

(II) o-aminophenol/o-aminothiophenol/PPA

SCHEME 1

/benzothiazol-2-yl rings substituted on the fourth position of quinoline nucleus act as an electron acceptor system.

\section{Result and Discussion}

2.1. Chemistry. The photoluminescence properties of 2-(1benzofuran-2-yl) quinoline-4-carboxylic acids (3a-b) have prompted us to replace the carboxyl group with fused heterocyclic ring system like benzoxazole $\mathbf{4}(\mathbf{a}-\mathbf{b})$ and benzothiazole $4(\mathbf{c}-\mathbf{d})$, and to study the effect of alteration on the photoluminescence properties. The intermediate compounds $3(\mathbf{a}-\mathbf{b})$ were prepared by reported method [16], and structures were confirmed by spectral data. The title compounds 2-(1-benzofuran-2-yl)-4-(1, 3-benzoxazol-2-yl/ 1,3benzothiazol-2-yl) quinolines (4a-d) were synthesized by reacting 2-(1-benzofuran-2-yl) quinoline-4-carboxylic acids (3a-b)with o-aminophenol and o-amino thiophenol, respectively, using polyphosphoric acid as cyclizing agent. The structures of newly synthesized compounds were confirmed by IR, ${ }^{1} \mathrm{HNMR},{ }^{13} \mathrm{CNMR}$, mass spectral data, and elemental analyses. The schematic representation of reaction has been shown in Scheme 1.

2.2. Fluorimetric Properties. In order to perform the spectral characterization of the new dyes, absorption and emission spectra of compounds $\mathbf{3}(\mathbf{a}-\mathbf{b})$ were recorded in two different solvents, namely, THF and DMSO (as these two compounds are insoluble in chloroform), and absorption and emission spectra of compounds $\mathbf{4}(\mathbf{a}-\mathbf{d})$ were recorded in $\mathrm{CHCl}_{3}$, THF, and DMSO. The absorption spectra have been shown in Figures 1(a)-1(c), and fluorescence spectra in Figures 2(a)-2(f) and the relevant data is tabulated in Table 1. All fluorescent probes exhibited a bathochromic shift of the emission peak with decreased intensity of emitted light on raising the polarity of solvents, and a related increase of the Stokes shift and decrease in quantum yield are observed. Fluorescent probes $\mathbf{3} \mathbf{a}$ and $\mathbf{3 b}$ emitted light in the blue region of the spectrum, and 2-(1benzofuran-2-yl)-6-chloroquinoline-4-carboxylic acid (3b) showed bathochromic shift by $11.5 \mathrm{~nm}$ when compared to 2-(1-benzofuran-2-yl) quinoline-4-carboxylic acid 3a. This may be due to the presence of electron releasing chloro substitution on the 6th position of quinoline ring system in compound $\mathbf{3 b}$, which acts as a chromophore. On replacing carboxylic group of 2-(1-benzofuran-2-yl) quinoline-4carboxylic acid with benzoxazole $\mathbf{4}(\mathbf{a}-\mathbf{b})$ and benzothiazole 4(c-d), we found bathochromic shift in emission peaks and this may be attributed to the electron accepting tendency of benzoxazole and benzothiazole ring system, which decreases the energy gap between LUMO $\left(\pi^{*}\right)$ and $\mathrm{HOMO}(\pi)$ leading to shift towards longer wavelength than compared to carboxylic acid. On increasing the solvent polarity, all compounds exhibited shift towards longer wavelength. The emission peaks are at lower energy or longer wavelength than compared to absorption peak; this loss of energy is due to a variety of dynamic processes, which occur following light absorption. The fluorophore is typically excited to the first singlet state $\left(\mathrm{S}_{1}\right)$, usually to an excited vibrational level within $\mathrm{S}_{1}$. The excess vibrational energy is rapidly lost to the solvent. If the fluorophore is excited to the second singlet state $\left(S_{2}\right)$, it rapidly decays to the $S_{1}$ state in $10^{-12} \mathrm{~s}$ due to internal conversion. Solvent effects shift the emission to still lower energy owing to stabilization of the excited state by the polar solvent 


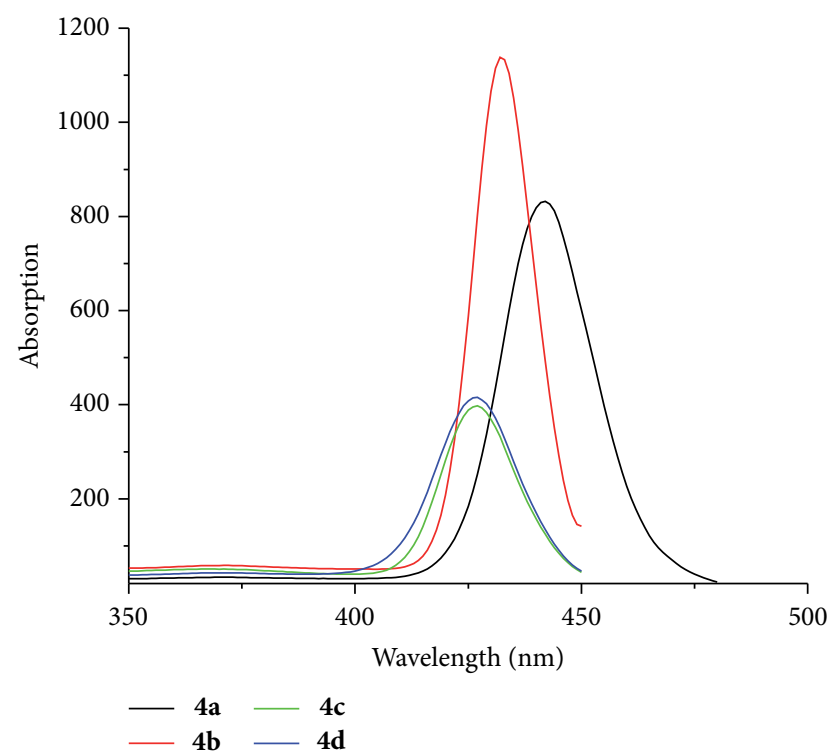

(a)

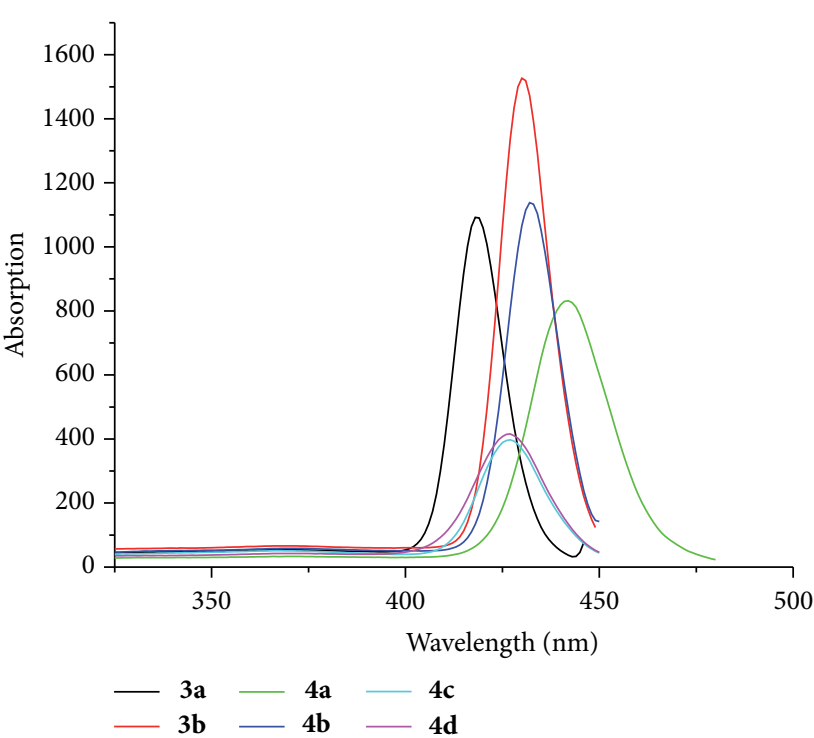

(b)

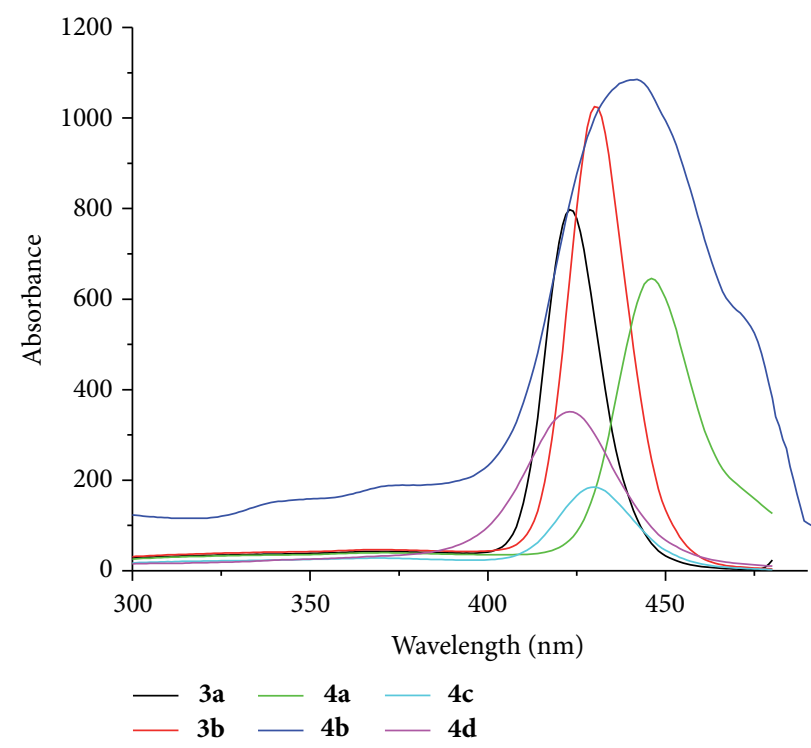

(c)

Figure 1: Absorption spectra of compounds 3(a-b) and 4(a-d) in different solvents; 1(a) chloroform, 1(b) THF, and 1(c) DMSO.

molecules. Typically, the fluorophore has a larger dipole moment in the excited state than in the ground state. Following excitation, the solvent dipoles can reorient or relax at that state, which lowers the energy of the excited state. As the solvent polarity is increased, this effect becomes larger, resulting in emission at lower energies or longer wavelengths [16].

From the absorption data (Table 1), it is evident that the absorption wavelengths are slightly varied or no variations are observed on increasing polarity of the solvents. This may be because absorption of light occurs in about $10^{-15} \mathrm{~s}$, a time that is too short for motion of the fluorophore or solvent. Absorption spectra are not affected by the decrease in the excited-state energy, which occurs after absorption has occurred [16].
Among the tested compounds, compound 4a emitted light in the green region in all three solvents $\mathrm{CHCl}_{3}, \mathrm{THF}$, and DMSO at wavelength of $490.4 \mathrm{~nm}, 518.2 \mathrm{~nm}$, and $522.4 \mathrm{~nm}$, respectively. Compound $\mathbf{4 b}, \mathbf{4 c}$, and $\mathbf{4 d}$ emitted light in the green region only in polar solvent DMSO.

\section{Experimental}

All the chemicals used were of analytical grade. Melting points were determined in open capillary tubes and are uncorrected. Purity of the compounds was checked by TLC on silica gel. The IR spectra were recorded on Nicolet-Impact410 FT-IR spectrometer, using $\mathrm{KBr}$ pellets. ${ }^{1} \mathrm{H}$ NMR spectra were recorded on a Bruker Supercon FT NMR (400 MHz) 


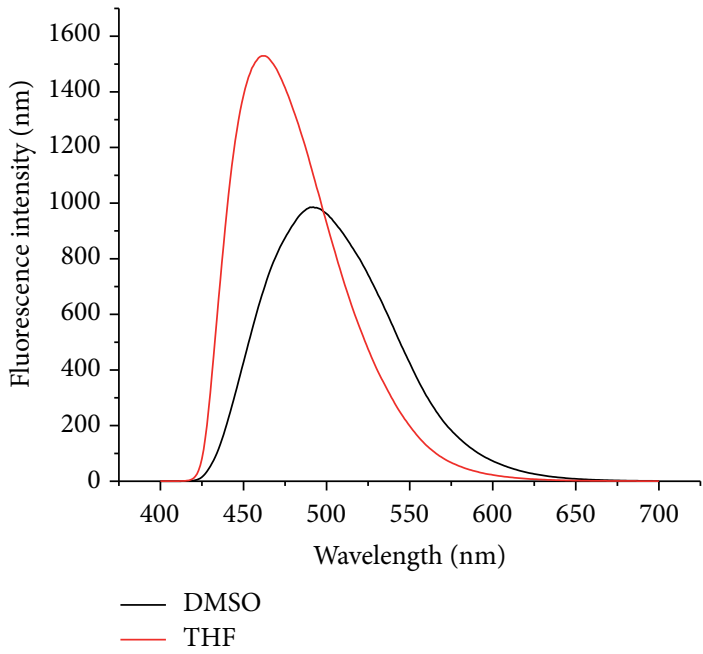

(a) Emission spectra of $\mathbf{3 a}$

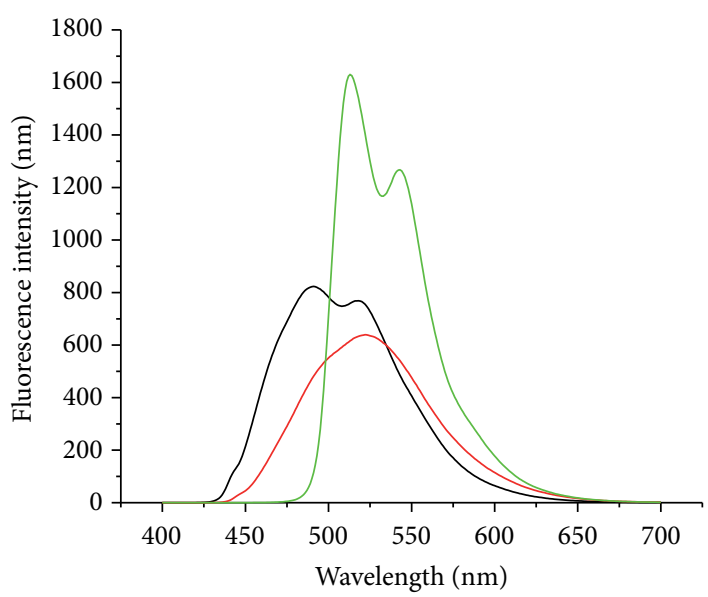

(c) Emission spectra of $\mathbf{4 a}$

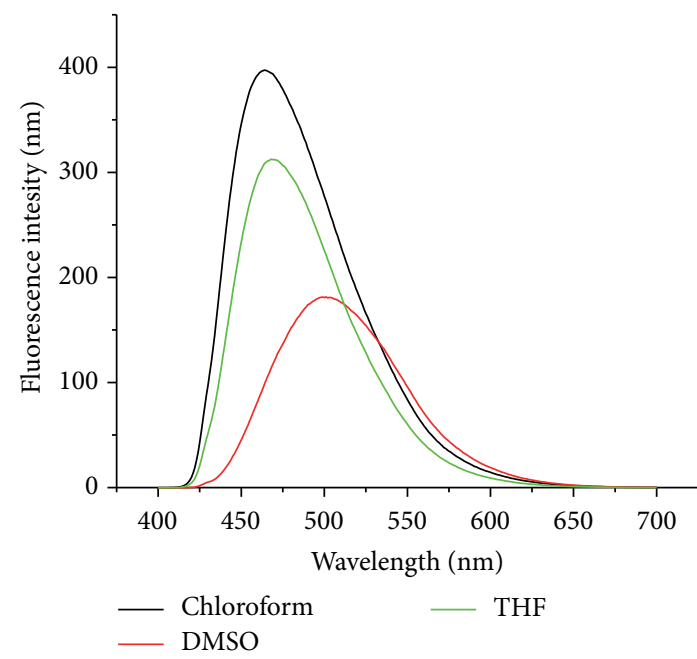

(e) Emission spectra of $\mathbf{4 c}$

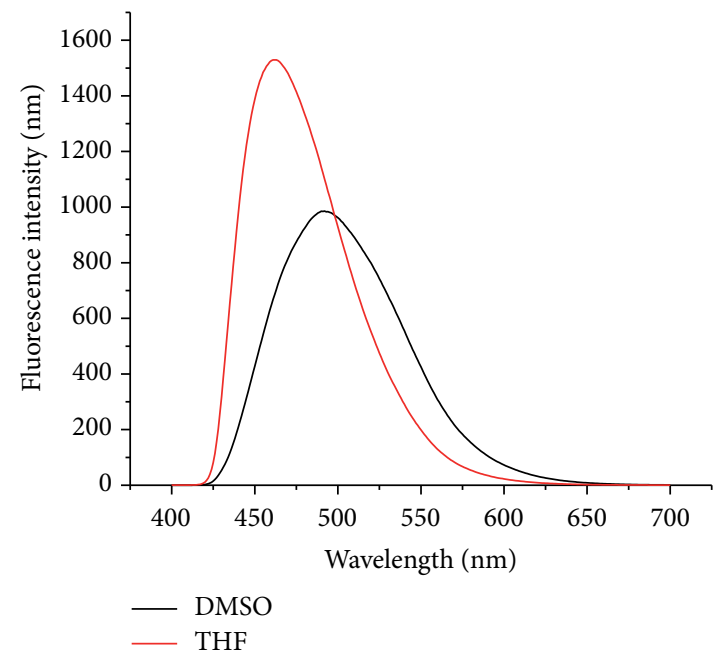

(b) Emission spectra of $\mathbf{3 b}$

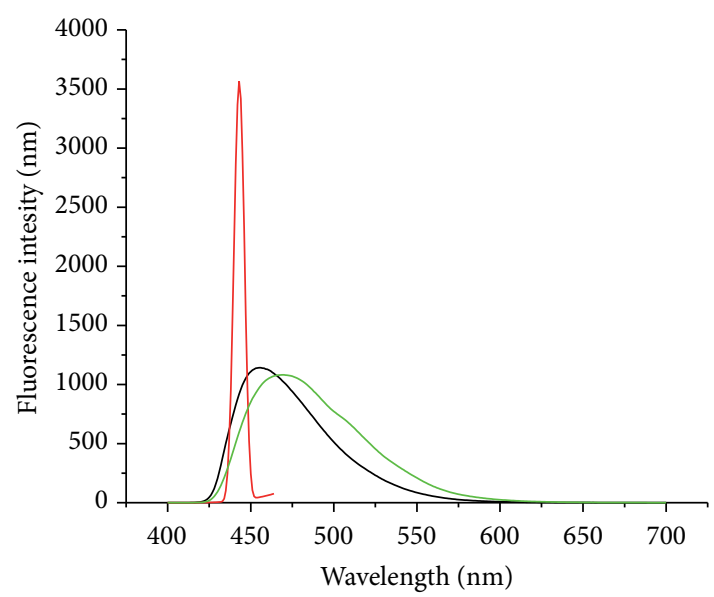

(d) Emission spectra of $\mathbf{4 b}$

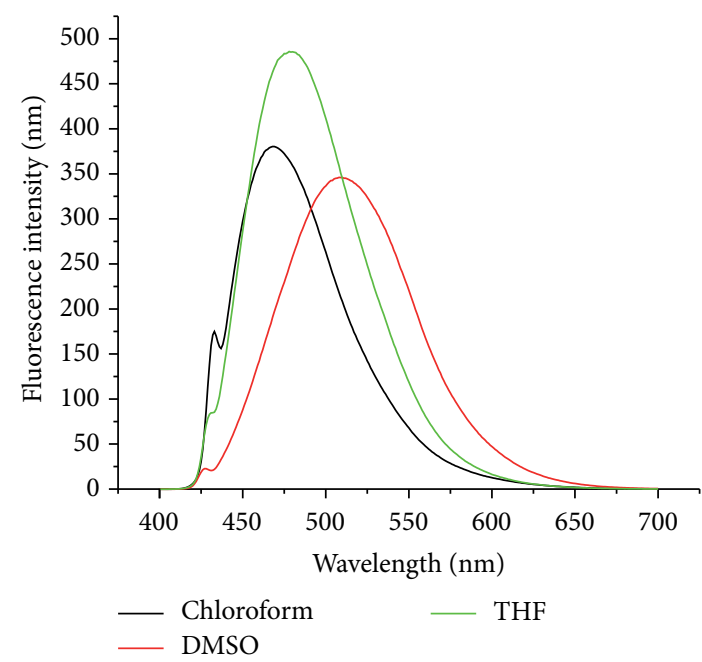

(f) Emission spectra of $\mathbf{4 d}$

FIgURE 2: Emission spectra of compounds $\mathbf{3}(\mathbf{a}-\mathbf{b})$ and $\mathbf{4}(\mathbf{a}-\mathbf{d})$ in different solvents. 
TABLE 1: Photoluminescence properties of compound (3a-b) and (4a-d).

\begin{tabular}{|c|c|c|c|c|c|c|}
\hline Compound & Solvent & Absorption $\lambda_{\max } \mathrm{nm}$ & Emission $\lambda_{\max } \mathrm{nm}$ & Molar absorpivity $\mathrm{Mol}^{-1} \mathrm{~cm}^{-1}$ & Stokes shift nm & Quantum yield $\Phi_{F}$ \\
\hline \multirow{2}{*}{$3 a$} & THF & 418.0 & 451.6 & $223.6 \times 10^{4}$ & 33.6 & 0.183 \\
\hline & DMSO & 423.2 & 483.8 & $153.9 \times 10^{4}$ & 60.6 & 0.165 \\
\hline \multirow{2}{*}{$3 \mathbf{b}$} & THF & 430.4 & 462.8 & $305.8 \times 10^{4}$ & 32.4 & 0.186 \\
\hline & DMSO & 430.4 & 491.8 & $197.3 \times 10^{4}$ & 61.4 & 0.181 \\
\hline \multirow{3}{*}{$4 a$} & Chloroform & 441.6 & 490.4 & $164.7 \times 10^{4}$ & 48.8 & 0.247 \\
\hline & THF & 446.0 & 518.2 & $201.0 \times 10^{4}$ & 72 & 0.243 \\
\hline & DMSO & 446.4 & 522.4 & $127.9 \times 10^{4}$ & 76 & 0.228 \\
\hline \multirow{3}{*}{$4 b$} & Chloroform & 432.0 & 485.8 & $228.4 \times 10^{4}$ & 53.8 & 0.184 \\
\hline & THF & 432.2 & 470.2 & $216.4 \times 10^{4}$ & 38 & 0.167 \\
\hline & DMSO & 442.0 & 512.0 & $713.2 \times 10^{4}$ & 70 & 0.132 \\
\hline \multirow{3}{*}{$4 c$} & Chloroform & 427.0 & 465.4 & $79.4 \times 10^{4}$ & 38.4 & 0.206 \\
\hline & THF & 426.8 & 468.2 & $62.5 \times 10^{4}$ & 41.4 & 0.205 \\
\hline & DMSO & 430.0 & 499.2 & $181.4 \times 10^{4}$ & 69.2 & 0.198 \\
\hline \multirow{3}{*}{$4 d$} & Chloroform & 427.0 & 468.2 & $76.1 \times 10^{4}$ & 41.2 & 0.143 \\
\hline & THF & 426.8 & 478.0 & $97.1 \times 10^{4}$ & 51.2 & 0.136 \\
\hline & DMSO & 423.6 & 510.6 & $69.2 \times 10^{4}$ & 87 & 0.134 \\
\hline
\end{tabular}

spectrometer in $\mathrm{CDCl}_{3}$ or DMSO- $d_{6}$ using TMS as an internal standard. The chemical shifts are expressed in $\delta$ units. Mass spectra were recorded on a JEOL SX 102/DA-6000 $(10 \mathrm{kV}) \mathrm{FAB}$ mass spectrometer.

\subsection{Synthesis of 2-(1-Benzofuran-2-yl) Quinoline-4- carboxylic Acid 3(a-b)}

3.1.1. General Procedure. The compounds $\mathbf{3 a - b}$ were synthesized by the Pfitzinger method [17], with the slight modification in procedure. After completion of the reaction, the reaction mixture was cooled to room temperature, diluted with cold water and extracted using ethyl acetate to suspend the impurities in organic layer. The aqueous layer was acidified with dilute hydrochloric acid and the resulting yellow solid mass was filtered and dried to get pure compound.

3.1.2. 2-(1-Benzofuran-2-yl) Quinoline-4-carboxylic Acid (3a). Yield, $88 \%$, m.p. $245-248^{\circ} \mathrm{C}$, (literature $248-50^{\circ} \mathrm{C}$ ) [17], IR $(\mathrm{KBr})\left(v, \mathrm{~cm}^{-1}\right), 3426.9(\mathrm{OH}), 1702.1(\mathrm{C}=\mathrm{O}), 1599,1510$, 1246: ${ }^{1} \mathrm{H}$ NMR (DMSO- $\left.d_{6}, 400 \mathrm{MHz}\right): 14.15$ (s, $\left.1 \mathrm{H}, \mathrm{COOH}\right)$, $8.70-8.72(d, J=8.4,1 \mathrm{H} \mathrm{Ar}-\mathrm{H}), 8.48(\mathrm{~s}, 1 \mathrm{H}$ quinoline $3 \mathrm{C}-\mathrm{H}), 8.18-8.20(d, J=8.4,1 \mathrm{H} \mathrm{Ar}-\mathrm{H}), 8.014-8.018(d$, $J=16,1 \mathrm{H}, \mathrm{Ar}-\mathrm{H}), 7.78-7.82(\mathrm{q}, 2 \mathrm{H}, \mathrm{Ar}-\mathrm{H}), 7.72-7.77(\mathrm{t}$, 1H, Ar-H), 7.45-7.49 (t, 1H,Ar-H), 7.34-7.38 (t, 1H, Ar-H). MS: $m / z=290.1(\mathrm{M}+1), 291.1(\mathrm{M}+2)$.

\subsubsection{2-(1-Benzofuran-2-yl)-6-chloroquinoline-4-carboxylic} Acid (3b). Yield, $76 \%$, m.p. $283-285^{\circ} \mathrm{C}$, IR $(\mathrm{KBr})\left(v, \mathrm{~cm}^{-1}\right)$ $3436(\mathrm{OH}), 1712(\mathrm{C}=\mathrm{O}), 1570,1514,720,640 .{ }^{1} \mathrm{H}$ NMR (DMSO- $\left.d_{6}, 400 \mathrm{MHz}\right): 13.85(\mathrm{~s}, 1 \mathrm{H}, \mathrm{COOH}) 8.80-8.82(d$, $J=8,1 \mathrm{H} \mathrm{Ar}-\mathrm{H}) 8.55$ (s, $1 \mathrm{H}$ quinoline $3 \mathrm{C}-\mathrm{H}), 8.17-8.20$ $(d, J=12,1 \mathrm{H} \mathrm{Ar}-\mathrm{H}), 7.94(\mathrm{~s}, 1 \mathrm{H}$, furan-H), 7.89-7.91 (d, $J=8,1 \mathrm{H}, \mathrm{Ar}-\mathrm{H}), 7.77-7.81(\mathrm{q}, 2 \mathrm{H}, \mathrm{Ar}-\mathrm{H}), 7.44-7.49(\mathrm{t}, 1 \mathrm{H}$,
Ar-H), 7.34-7.37 (t, 1H, Ar-H). MS: $m / z=324.0(\mathrm{M}+1)$. Anal. Calc. (in \%) for $\mathrm{C}_{18} \mathrm{H}_{10} \mathrm{NO}_{3}$ : C, 67.05; H, 2.48; N, 4.32. Found: C, 67.25; H, 2.68; N, 4.43.

\subsection{Synthesis of 2-(1-Benzofuran-2-yl)-4-(1,3-benzoxazol-} 2-yl/1,3-benzothiazol-2-yl) Quinoline Derivatives 4(a-d)

3.2.1. General Procedure. A mixture of 2-(1-benzofuran-2yl) quinoline-4-carboxylic acid (3a-b) $(0.5 \mathrm{mmol})$ and oamino phenol/o-amino thiophenol was dissolved in $15 \mathrm{gm}$ of polyphosphoric acid. The reaction mixture was heated with stirring at about $120-130^{\circ} \mathrm{C}$ for $8 \mathrm{hrs}$. After completion of the reaction, the reaction mixture was cooled, poured on to crushed ice, and neutralized using aqueous $\mathrm{NaOH}$ solution. The resulting solid was dried and purified by extracting using petroleum ether.

\subsubsection{2-(1-Benzofuran-2-yl)-4-(1, 3-benzoxazol-2-yl)}

Quinoline (4a). Yield, 66\%, m.p. $162-164^{\circ} \mathrm{C},{ }^{1} \mathrm{H}$ NMR (DMSO- $\left.d_{6}, 400 \mathrm{MHz}\right)$ : 9.45-9.49 $(d, J=16,1 \mathrm{H}), 8.89$ $(\mathrm{s}, 1 \mathrm{H}), 8.21-8.29(\mathrm{t}, J=32,1 \mathrm{H}), 7.958-8.009(\mathrm{~m}, 4 \mathrm{H})$, 7.831-7.899 (m, 3H), 7.602-7.644 (m, 2H), 7.469-7.581 (m, $1 \mathrm{H}), 7.361-7.402(\mathrm{q}, 1 \mathrm{H}),{ }^{13} \mathrm{CNMR}\left(\mathrm{CDCl}_{3}, 100.5 \mathrm{MHz}\right)$ : 102.4 (1C), 103.2 (1C), 110.6 (1C), 111.5(1C), 119.1 (1C), 120.0 (1C), 120.9 (1C), 122.9 (1C), 123.8 (2C), 124.9 (1C), 125.1 (1C), 126.9 (1C), 128.3 (1C), 128.9(1C), 130.1 (1C), 142.2 (1C), 144.9(1C), 147.5 (1C), 149.9 (1C), 150.0 (1C), 155.3 (1C), 158.1 (1C), 162.7 (1C), MS: $m / z=363.1(\mathrm{M}+1)$, $364.2(\mathrm{M}+2)$. Anal.Calc. (in \%) for $\mathrm{C}_{24} \mathrm{H}_{14} \mathrm{~N}_{2} \mathrm{O}_{2}$ : C, 79.86; H, 3.86; N, 7.72. Found: C, 79.40; H, 3.95; N, 7.62.

3.2.3. 2-(1-Benzofuran-2-yl)-4-(1, 3-benzoxazol-2-yl)-6-chloroquinoline (4b). Yield, 58\%, m.p. $145-148^{\circ} \mathrm{C},{ }^{1} \mathrm{H}$ NMR $\left(\mathrm{DMSO}-d_{6}, 400 \mathrm{MHz}\right): 9.599$ (s, 1H), 8.898 (s, 1H), 
8.201-8.223 $(d, J=8.8,1 \mathrm{H}), 7.993-7.995(d, J=0.8$, 1H), 7.684-7.977 (m, 5H), 7.401-7.484 (m, 2H), 7.324-7.343 $(\mathrm{t}, 1 \mathrm{H}), 7.25-7.268(\mathrm{~m}, 1 \mathrm{H}),{ }^{13} \mathrm{CNMR}\left(\mathrm{CDCl}_{3}, 100.5 \mathrm{MHz}\right)$ : 102.4 (1C), 103.2 (1C), 110.6 (1C), 111.5 (1C), 119.1 (1C), 120.0 (1C), 120.9 (1C), 122.9 (1C), 123.8 (2C), 124.9 (1C), 125.1 (1C), 125.8 (1C), 130.1 (1C), 131.2 (1C), 132.6 (1C), 142.2 (1C), 144.9 (1C), 147.5 (1C), 149.9 (1C), 150.0 (1C), 155.3 (1C), 158.1 (1C), 162.7 (1C). MS: $m / z=397.8(\mathrm{M}+$ 1), $399.8(\mathrm{M}+2)$. Anal.Calc. (in \%) for $\mathrm{C}_{24} \mathrm{H}_{13} \mathrm{ClN}_{2} \mathrm{O}_{2}$ : C, 72.57; H, 3.25; N, 7.02. Found: C, 72.23; H, 3.85; N, 6.60 .

3.2.4. 2-(1-Benzofuran-2-yl)-4-(1, 3-benzothiazol-2-yl) Quinoline (4c). Yield, 63\%, m.p. $178-180^{\circ} \mathrm{C},{ }^{1} \mathrm{H}$ NMR (DMSO$\left.d_{6}, 400 \mathrm{MHz}\right): 8.90-8.98(d, J=32,1 \mathrm{H}), 8.56(\mathrm{~s}, 1 \mathrm{H})$, $8.21-8.42(\mathrm{~m}, J=84,3 \mathrm{H}), 8.02(\mathrm{~s}, 1 \mathrm{H}), 7.939-7.963(\mathrm{q}$, $1 \mathrm{H}), 7.787-7.844(\mathrm{~m}, 3 \mathrm{H}), 7.626-7.728(\mathrm{~m}, 2 \mathrm{H}), 7.465-7.504$ $(\mathrm{q}, 1 \mathrm{H}), 7.361-7.463(\mathrm{q}, 1 \mathrm{H}),{ }^{13} \mathrm{CNMR}\left(\mathrm{CDCl}_{3}, 100.5 \mathrm{MHz}\right)$ : 102.4 (1C), 103.2 (1C), 111.5 (1C), 119.1 (1C), 120.0 (1C), 120.9 (1C), 121.8 (1C), 122.9 (1C), 123.8 (1C), 125.1 (1C), 125.6 (1C), 126.0 (1C), 126.9 (1C), 128.3 (1C), 128.9 (1C), 130.1 (1C), 135.5 (1C), 144.9 (1C), 147.5 (1C), 149.9 (1C), 153.5 (1C), 155.3 (1C), 158.1 (1C), 162.7 (1C), MS: $m / z=$ $379.4(\mathrm{M}+1)$. Anal. Calc. (in \%) for $\mathrm{C}_{24} \mathrm{H}_{14} \mathrm{~N}_{2} \mathrm{OS}$ : C, 76.16; H, 3.69; N, 7.39. Found: C, 76.03; H, 3.55; N, 7.30 .

\subsubsection{2-(1-Benzofuran-2-yl)-4-(1, 3-benzothiazol-2-yl)-6-}

chloroquinoline (4d). Yield, 70\%, m.p. $165-168^{\circ} \mathrm{C},{ }^{1} \mathrm{H}$ NMR (DMSO- $d_{6}, 400 \mathrm{MHz}$ ): 9.16 (s, 1H), 8.78 (s, 1H), 8.201-8.223 $(d, J=8.8,1 \mathrm{H}), 7.993-7.995(d, J=0.8,1 \mathrm{H})$, 7.686-7.979 (m, 5H), 7.401-7.484 (m, 2H), 7.324-7.343 (t, $1 \mathrm{H}), 7.25-7.268(\mathrm{~m}, 1 \mathrm{H}),{ }^{13} \mathrm{CNMR}\left(\mathrm{CDCl}_{3}, 100.5 \mathrm{MHz}\right)$ : 102.4 (1C), 103.2 (1C), 111.5 (1C), 119.1 (1C), 120.0 (1C), 120.7 (1C), 121.8, 122.9 (1C), 123.8 (1C), 125.1 (1C), 125.6 (1C), 125.9 (1C), 126.0, 130.5 (1C), 131.5 (1C), 132.6 (1C), $135.5,144.9$ (1C), 146.1 (1C), 149.9 (1C), 153.5, 155.3 (1C), 158. 1 (1C), 162.7 (1C). MS: $m / z=413.9(\mathrm{M}+$ 1), $414.9(\mathrm{M}+2)$. Anal. Calc. (in \%) for $\mathrm{C}_{24} \mathrm{H}_{13} \mathrm{ClN}_{2} \mathrm{OS}$ : $\mathrm{C}, 69.8 ; \mathrm{H}, 3.14 ; \mathrm{N}, 6.78$. Found: C, 69.4; H, 3.22; N, 6.67 .

3.3. Fluorescent Studies. The fluorescence spectra were recorded on F-7000 spectrofluorometer (Hitachi) with Xenon flash lamp. The spectra were recorded by preparing the solutions of test compounds at the concentration of $5 \times$ $10^{-6} \mathrm{~mole} / \mathrm{mL}$ in three different solvents $\mathrm{CHCl}_{3}, \mathrm{THF}$, and DMSO. The solutions of each sample were scanned after keeping it at room temperature for about $1 \mathrm{~h}$. The emission and excitation wavelength data are recorded using glass cuvettes. The emission quantum yields were determined at $\lambda_{\text {exc }}$ corresponding to the maximum of the absorption band $\left(\lambda_{\max }\right)$ of quinine sulphate in $0.1 \mathrm{M}$ $\mathrm{H}_{2} \mathrm{SO}_{4}$, which was used as a fluorimetric standard $\left(\Phi_{F}=\right.$ $0.54)$.

\section{Conclusion}

In conclusion, we have demonstrated a convenient and efficient method for the synthesis of an important class of 2 (1-benzofuran-2-yl)-4-(1,3-benzoxazol-2-yl/ benzothiazol$2-y l)$ quinolines $(\mathbf{4 a}-\mathbf{d})$ by reacting 2-(1-benzofuran-2-yl) quinoline-4-carboxylic acids (3a-b) with o-aminophenol and o-aminothiophenol respectively using PPA as cyclizing agent. All synthesized compounds displayed good fluorescent properties.

\section{Acknowledgments}

The authors are thankful to USIC, Karnataka University Dharwad for providing fluorescence spectra. One of the authors (S. Shankerro) is thankful to DST-Government of India, for awarding Inspire fellowship.

\section{References}

[1] Z. He, G. H. W. Milburn, K. J. Baldwin, D. A. Smith, A. Danel, and P. Tomasik, "Efficient blue photoluminescence of pyrazolo-[3,4-b]-quinoline derivatives and the energy transfer in polymer matrices," Journal of Luminescence, vol. 86, no. 1, pp. $1-14,2000$.

[2] M. Sankaran, C. Kumarasamy, U. Chokkalingam, and P. S. Mohan, "Synthesis, antioxidant and toxicological study of novel pyrimido quinoline derivatives from 4-hydroxy-3-acyl quinolin-2-one," Bioorganic and Medicinal Chemistry Letters, vol. 20, no. 23, pp. 7147-7151, 2010.

[3] X. Zhang, A. S. Shetty, and S. A. Jenekhe, "Electroluminescence and photophysical properties of polyquinolines," Macromolecules, vol. 32, no. 22, pp. 7422-7429, 1999.

[4] Z. He, G. H. W. Milburn, A. Danel, A. Puchala, P. Tomasik, and D. Rasala, "Blue electroluminescence of novel pyrazoloquinoline and bispyrazolopyridine derivatives in doped polymer matrices," Journal of Materials Chemistry, vol. 7, no. 12, pp. 2323-2325, 1997.

[5] D. A. Pearce, N. Jotterand, I. S. Carrico, and B. Imperiali, "Derivatives of 8-hydroxy-2-methylquinoline are powerful prototypes for zinc sensors in biological systems," Journal of the American Chemical Society, vol. 123, no. 21, pp. 5160-5161, 2001.

[6] M. Sameiro and T. Gonçalves, "Fluorescent labeling of biomolecules with organic probes," Chemical Reviews, vol. 109, no. 1, pp. 190-212, 2009.

[7] E. A. Arriaga, Y. Zhang, and N. J. Dovichi, "Use of 3-(pcarboxybenzoyl) quinoline-2-carboxaldehyde to label amino acids for high-sensitivity fluorescence detection in capillary electrophoresis," Analytica Chimica Acta, vol. 299, no. 3, pp. 319-326, 1995.

[8] R. Y. Tsien, "New calcium indicators and buffers with high selectivity against magnesium and protons: design, synthesis, and properties of prototype structures," Biochemistry, vol. 19, no. 11, pp. 2396-2404, 1980.

[9] P. Jiang and Z. Guo, "Fluorescent detection of zinc in biological systems: recent development on the design of chemosensors and biosensors," Coordination Chemistry Reviews, vol. 248, no. 1-2, pp. 205-229, 2004.

[10] B. Berlman, Handbook of Fluorescence Spectra of Aromatic Molecules, Academic Press, New York, NY, USA, 1971. 
[11] S. Anderson, P. N. Taylor, and G. L. B. Verschoor, "Benzofuran trimers for organic electroluminescence," Chemistry. A European Journal, vol. 10, no. 2, pp. 518-527, 2004.

[12] J. R. Hwu, K. S. Chuang, S. H. Chuang, and S. C. Tsay, "New benzo[b]furans as electroluminescent materials for emitting blue light," Organic Letters, vol. 7, no. 8, pp. 1545-1548, 2005.

[13] M. K. Leung, C. C. Chang, M. H. Wu et al., "6-N,Ndiphenylaminobenzofuran-derived pyran containing fluorescent dyes: a new class of high-brightness red-light-emitting dopants for OLED," Organic Letters, vol. 8, no. 12, pp. 2623-2626, 2006.

[14] M. Kandaz, O. Güney, and F. B. Senkal, "Fluorescent chemosensor for $\mathrm{Ag}(\mathrm{I})$ based on amplified fluorescence quenching of a new phthalocyanine bearing derivative of benzofuran," Polyhedron, vol. 28, no. 14, pp. 3110-3114, 2009.

[15] O. Oter, K. Ertekin, C. Kirilmis, M. Koca, and M. Ahmedzade, "Characterization of a newly synthesized fluorescent benzofuran derivative and usage as a selective fiber optic sensor for Fe(III)," Sensors and Actuators, B, vol. 122, no. 2, pp. 450-456, 2007.

[16] J. R. Lakowicz, Solvent Effects on Emission Spectra, Principles of Fluorescence Spectroscopy, Chapter 6, Kluwer Academic Publishers, New York, NY, USA, 2nd edition, 1999.

[17] B. I. Ardashev and V. P. Gaidzhurova, "Anlogs of atophan containing furan analogs," Khimiya Geterotsiklichskikhi Soedineii, vol. 4, pp. 202-203, 1968. 

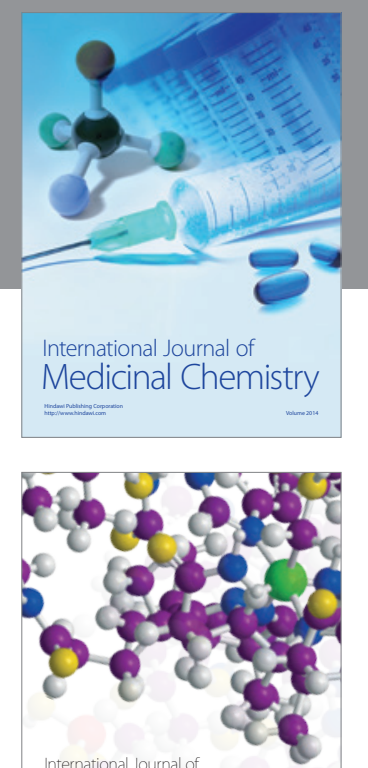

\section{Carbohydrate} Chemistry

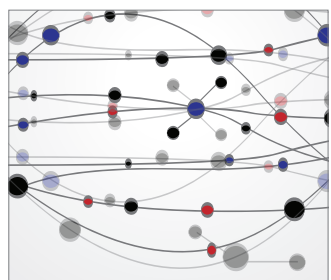

The Scientific World Journal
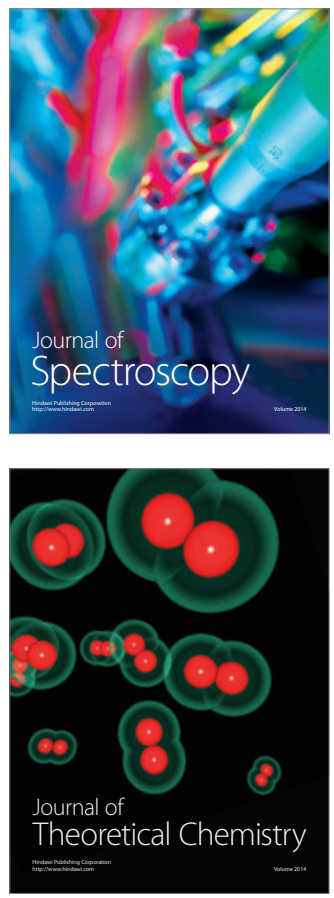
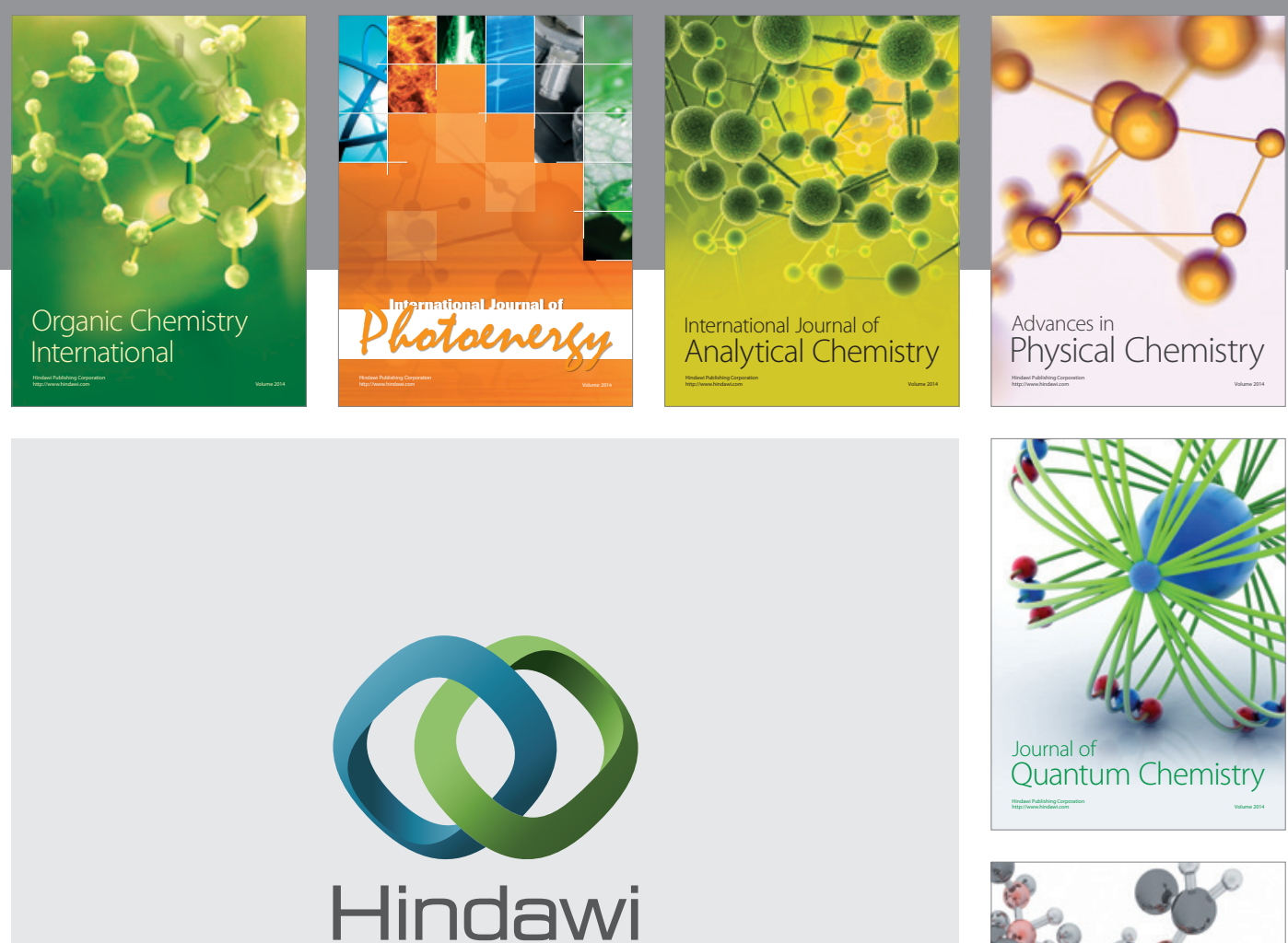

Submit your manuscripts at

http://www.hindawi.com

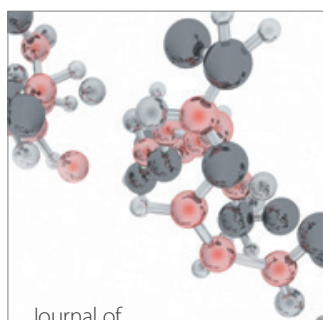

Analytical Methods

in Chemistry

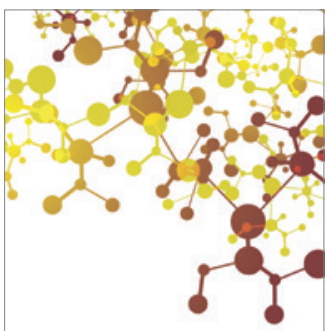

Journal of

Applied Chemistry

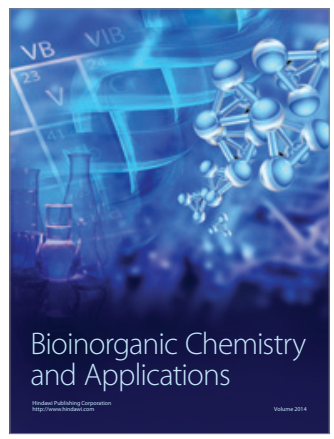

Inorganic Chemistry
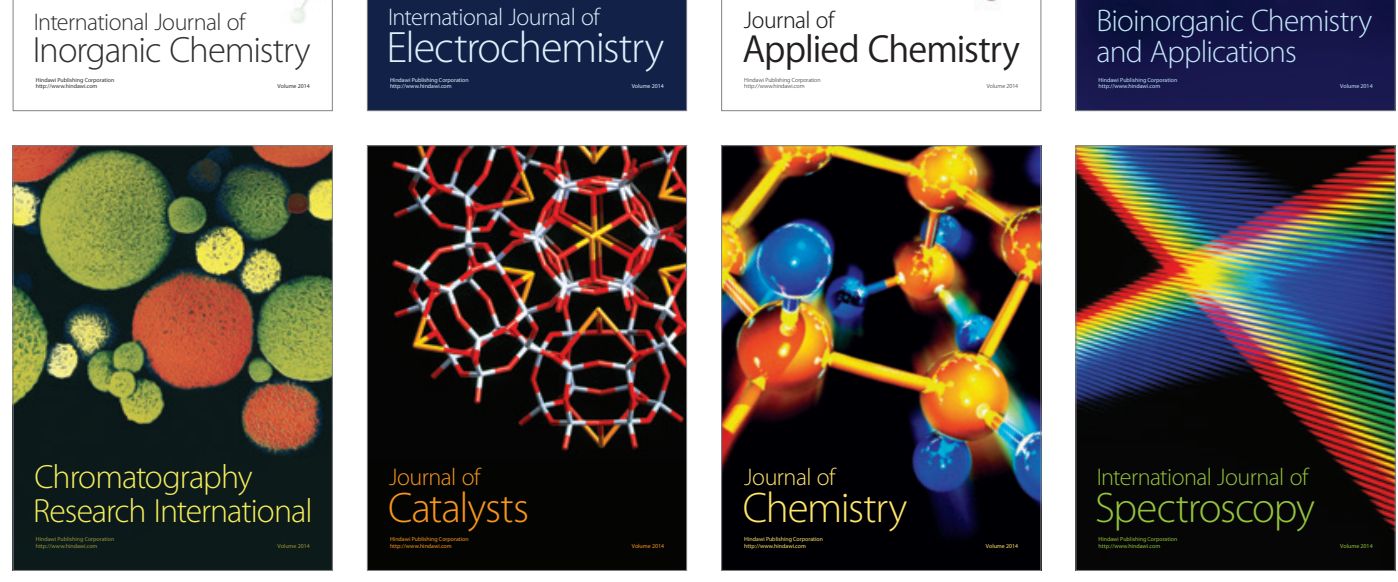